\title{
Anatomic and clinical risk factors for pulmonary embolism in patients with deep venous thrombosis of the lower extremity
}

\author{
Bomina Paik, Jin Hyun Joh, Ho-Chul Park \\ Department of Surgery, Kyung Hee University Hospital at Gangdong, Kyung Hee University School of Medicine, Seoul, Korea
}

\begin{abstract}
Purpose: Iliac vein compression is a known culprit of deep vein thrombosis (DVT). In contrast, the compression may prevent the pulmonary embolism (PE). The aim of this study was to evaluate the anatomic and clinical risk factors of PE in patients with lower extremity DVT.

Methods: PE was evaluated using chest computed tomography in patients with lower extremity DVT. The patients were classified into group I (DVT without PE) and group II (DVT with PE) and analyzed to clarify the anatomic and clinical risk factors associated with PE in patients with DVT. As the anatomic factor, the shortest length between the common iliac artery (CIA) and spinal body (SB) was measured. Statistical analyses utilized the multivariable logistic regression model, and receiver operating characteristic (ROC) curve analysis.

Results: We examined 114 patients lage; $62.7 \pm 16.9$ years, $41.7 \%$ men) with DVT with/without PE. The prevalence of concurrent DVT with PE was 52.6\%. Blood tests showed no difference between the 2 groups. Of all the assessed patients' characteristics, only infection was significantly and independently associated with $P E(P=0.04)$. The shortest length between $\mathrm{CIA}$ and SB was $6.7 \pm 3.5 \mathrm{~mm}$ in group I and $11.3 \pm 3.7 \mathrm{~mm}$ in group II $(\mathrm{P}<0.001)$. ROC curve analysis showed that 7.6 $\mathrm{mm}$ was the cut-off value for the anatomic risk of $\mathrm{PE}$.

Conclusion: Infection was significantly associated with concurrent DVT and PE. The shortest length between CIA and SB $(<7.6 \mathrm{~mm}$ ) may prevent PE in patients with DVT.

[Ann Surg Treat Res 2017;92(5):365-369]
\end{abstract}

Key Words: Venous thrombosis, Pulmonary embolism, Iliac vein, Risk factor

\section{INTRODUCTION}

Venous thromboembolism (VTE) is a major medical problem. VTE includes deep vein thrombosis (DVT) of the leg or pelvis and pulmonary embolism (PE). The annual incidence rates of VTE range from 104 to 183 per 100,000 person-years [1]. The incidence appears to be similar or higher among AfricanAmericans and lower among Asian- and Native-Americans [2]. In a Korean epidemiologic study, the annual incidence per 100,000 individuals was 8.83 to 13.8 [3].

$\mathrm{PE}$ is common in patients with DVT. Lung scintigraphy and angiographic abnormalities suggesting PE have been reported in $40 \%$ to $50 \%$ of patients with DVT [4]. Although these patients had no PE-related symptoms, several studies reported that symptomatic PE was more frequently found among patients treated for DVT who had asymptomatic PE than in those without PE [5]. Hypotension and circulatory arrest are associated with acute, massive PE.

Compression of the left common iliac vein (LCIV) by the right common iliac artery (RCIA) is a risk factor for development of lower extremity DVT (LEDVT). A causal mechanism is that chronic pulsation of the RCIA results in venous spur
Received September 19, 2016, Reviewed September 27, 2016,

Accepted December 20, 2016

Corresponding Author: Jin Hyun Joh

Department of Surgery, Kyung Hee University Hospital at Gangdong, Kyung Hee University School of Medicine, 892 Dongnam-ro, Gangdonggu, Seoul 05278, Korea

Tel: +82-2-440-6261, Fax: +82-2-440-6296

E-mail: jhjoh@khu.ac.kr
Copyright (C) 2017, the Korean Surgical Society

(c) Annals of Surgical Treatment and Research is an Open Access Journal. All articles are distributed under the terms of the Creative Commons Attribution NonCommercial License (http://creativecommons.org/licenses/by-nc/4.0/) which permits unrestricted non-commercial use, distribution, and reproduction in any medium, provided the original work is properly cited. 
formation in the LCIV. A comparison of limbs with left DVT to limbs without left DVT suggests that iliac vein compression may be associated with a higher percentage of left-sided DVT [6]. In contrast, the compression may prevent the thrombus from migrating into the pulmonary circulation. In a study of anatomic consideration, patients with an ipsilateral common iliac vein (CIV) lumen $\leq 4 \mathrm{~mm}$ had a lower risk of developing symptomatic PE compared with patients with a CIV lumen exceeding $4 \mathrm{~mm}$ [7]. However, anatomic and clinical risk factors of PE in patients with LEDVT are unclear, and were investigated presently.

\section{METHODS}

A retrospective review was performed of patients with LEDVT with or without PE. LEDVT was diagnosed with duplex ultrasound (Zonare Medical Systems, Mountain View, CA, USA) using a 5-9 $\mathrm{MHz}$ linear probe in adjunct with $\mathrm{CT}$ of the lower extremities. Chest $\mathrm{CT}$ was utilized for the evaluation of $\mathrm{PE}$.

Patients were divided into 2 groups. Group I included patients with LEDVT without PE and group II included those with both LEDVT and PE. LEDVT included both unilateral (right or left) and bilateral DVT, with thrombus existing anywhere between calf veins and iliac veins. In group I, the absence of PE was confirmed by chest CT. For patients to be classified in group II, the existence of $\mathrm{PE}$ anywhere from the main trunk to periphery of the pulmonary artery on chest $\mathrm{CT}$ was necessary.

We collected clinical risk factors including age, sex, body mass index (BMI), diabetes, hypertension, previous DVT, history of varicose vein, history of surgery, infection, pneumonia, coronary artery disease, chronic renal failure, and paralysis. Coronary artery disease was defined as the known coronary arterial disease on medication or history of intervention in coronary artery. Chronic renal failure was defined as end-stage renal disease on dialysis.

For evaluation of the anatomic factor, the shortest length between the posterior wall of the common iliac artery (CIA) and the anterior border of the spinal body (SB) was measured using the electronic caliper function featured in a picture archiving and communication system in the transverse view of CT scans. Fig. 1 shows the measurement method. The same method was incorporated in the case with a left-sided inferior vena cava (IVC) or other types of IVC abnormalities.

For the statistical analyses, data were analyzed using the IBM SPSS Statistics ver. 19.0 (IBM Co., Armonk, NY, USA). Independent t-test, chi-square test, multiple logistic regression model, and receiver operating characteristics (ROCs) curve were used to evaluate clinical risk factors and anatomic feature. All $\mathrm{P}$-values were considered significant if $<0.05$.

\section{RESULTS}

We collected the data from 114 patients with LEDVT. Fifty four cases did not have co-existing PE (group I), and 60 cases $\operatorname{did}$ (group II). Table 1 shows the patient demographics. The mean age of patients (66 females) was $62.7 \pm 16.9$ years (range, 21-92 years). The mean BMI was $24.2 \pm 3.9 \mathrm{~kg} / \mathrm{m}^{2}$ and the mean height was $160.9 \pm 9.8 \mathrm{~cm}$. DVT was found in only one leg in 96 patients (84.2\%): in the right leg in 19 patients $(16.7 \%)$ and in the left leg in 77 patients (67.5\%). Bilateral DVT was observed in 18 patients $(15.8 \%)$. PE was detected in 60 patients $(52.6 \%)$ on chest CT: in the right lung in 11 patients $(18.3 \%)$, in the left lung in 8 patients (13.3\%), and in both lungs in 41 patients (68.4\%).

Clinical risk factors of the 2 groups are shown in Table 2. Diabetes and hypertension were more common in the group without $\mathrm{PE}(\mathrm{P}=0.01$ and $\mathrm{P}=0.03$, respectively), while infection $(\mathrm{P}<0.01)$ was more common in group with $\mathrm{PE}$. Chronic renal failure $(P=0.10)$ and bed-ridden status $(P=0.10)$ were
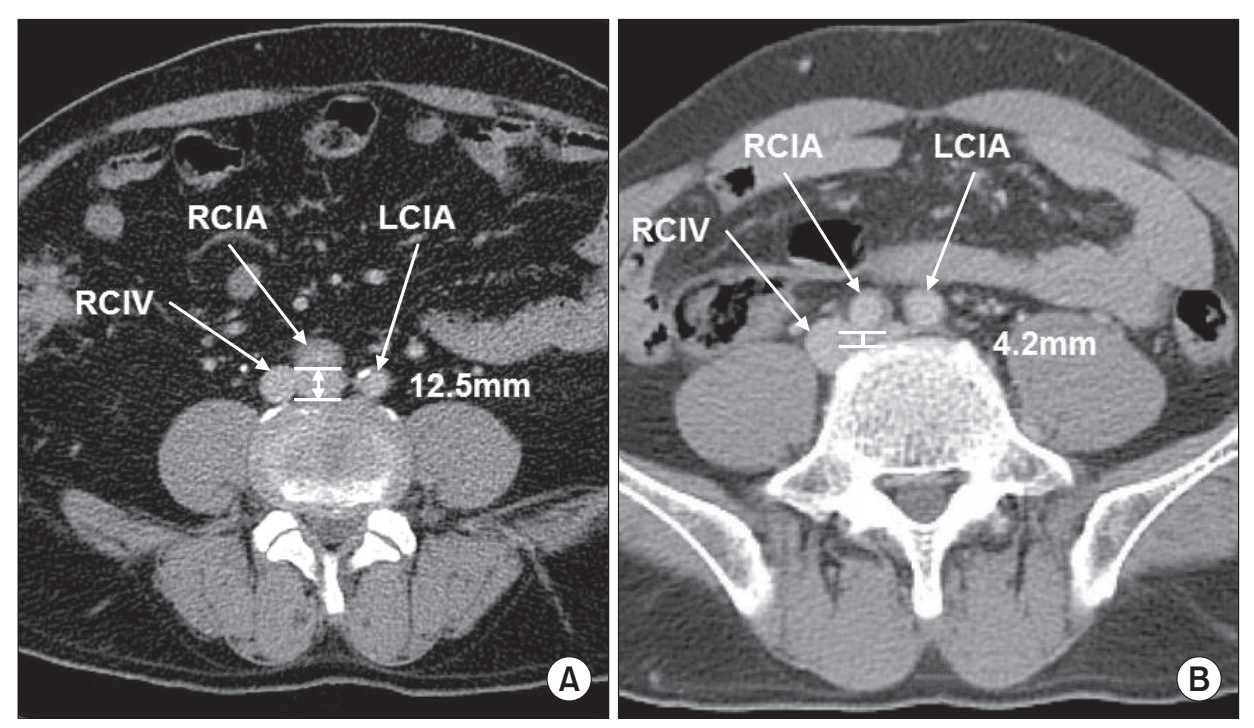

Fig. 1. Measurement of the shortest length between the posterior wall of the common iliac artery and anterior border of the spinal body: (A) $12.5 \mathrm{~mm}$, (B) $4.2 \mathrm{~mm}$. RICV, right common iliac vein; RCIA, right common iliac artery; LCIA, left common iliac artery. 
Table 1. Patient demographics $(n=114)$

\begin{tabular}{|c|c|c|c|}
\hline Demographics & $\begin{array}{c}\text { Group I } \\
(\mathrm{PE}-)\end{array}$ & $\begin{array}{l}\text { Group II } \\
(\mathrm{PE}+)\end{array}$ & Total \\
\hline Age (yr) & $64.2 \pm 18.2$ & $61.4 \pm 15.7$ & $62.7 \pm 16.9$ \\
\hline $\begin{array}{l}\text { Body mass index } \\
\left(\mathrm{kg} / \mathrm{m}^{2}\right)\end{array}$ & $24.0 \pm 3.8$ & $24.2 \pm 3.9$ & $24.2 \pm 3.9$ \\
\hline Height & $160.6 \pm 9.4$ & $161.1 \pm 10.1$ & $160.9 \pm 9.8$ \\
\hline $\begin{array}{l}\text { Deep vein } \\
\text { thrombosis }\end{array}$ & $54(47.4)$ & $60(52.6)$ & $114(100)$ \\
\hline Right leg & $5(9.3)$ & $14(23.3)$ & $19(16.7)$ \\
\hline Left leg & $45(83.3)$ & $32(53.3)$ & $77(67.5)$ \\
\hline Both legs & $4(7.4)$ & $14(23.4)$ & $18(15.8)$ \\
\hline \multicolumn{4}{|c|}{ Pulmonary embolism } \\
\hline Right lung & - & $11(18.3)$ & $11(18.3)$ \\
\hline Left lung & - & $8(13.3)$ & $8(13.3)$ \\
\hline Both lungs & - & $41(68.4)$ & $41(68.4)$ \\
\hline
\end{tabular}

Values are presented as mean \pm standard deviation or number (\%). Group I, DVT without PE; group II, DVT with PE; PE, pulmonary embolism; DVT, deep vein thrombosis.

Table 2. Clinical risk factors

\begin{tabular}{|c|c|c|c|}
\hline Risk factor & $\begin{array}{l}\text { Group I } \\
(\mathrm{PE}-)\end{array}$ & $\begin{array}{l}\text { Group II } \\
(\mathrm{PE}+)\end{array}$ & P-value \\
\hline No. of patients & $54(47.4)$ & $60(52.6)$ & \\
\hline Age (yr) & $64.2 \pm 18.2$ & $61.4 \pm 15.7$ & $0.377^{\mathrm{a})}$ \\
\hline Body mass index $\left(\mathrm{kg} / \mathrm{m}^{2}\right)$ & $24.0 \pm 3.8$ & $24.2 \pm 3.9$ & $0.778^{\mathrm{a})}$ \\
\hline Diabetes (no: yes) & $45: 9$ & $58: 2$ & $0.016^{\mathrm{b})}$ \\
\hline Hypertension, no: yes & $37: 17$ & $51: 9$ & $0.036^{\mathrm{b})}$ \\
\hline Varicose vein, no: yes & $53: 1$ & $59: 1$ & $>0.999^{\mathrm{b})}$ \\
\hline Surgery, no:yes & $35: 19$ & $40: 20$ & $0.835^{b)}$ \\
\hline Infection, no:yes & $52: 2$ & $47: 13$ & $0.005^{b)}$ \\
\hline Pneumonia, no:yes & $50: 4$ & $58: 2$ & $0.420^{\mathrm{b})}$ \\
\hline $\begin{array}{l}\text { Coronary artery disease, } \\
\text { no:yes }\end{array}$ & 49:5 & $58: 2$ & $0.253^{\text {b) }}$ \\
\hline $\begin{array}{l}\text { Congestive heart failure, } \\
\text { no:yes }\end{array}$ & $50: 4$ & $58: 2$ & $0.420^{b)}$ \\
\hline $\begin{array}{l}\text { Chronic renal failure, } \\
\text { no:yes }\end{array}$ & 49:5 & $59: 1$ & $0.100^{\mathrm{b})}$ \\
\hline Bed-ridden status, no:yes & $51: 3$ & $60: 1$ & $0.103^{b)}$ \\
\hline History of DVT, no:yes & $29: 25$ & $33: 27$ & $0.890^{\mathrm{b})}$ \\
\hline Paralysis, no:yes & $52: 2$ & 60:0 & $0.222^{\mathrm{b})}$ \\
\hline
\end{tabular}

Values are presented as number $(\%)$, mean \pm standard deviation, or number.

Group I, DVT without PE; group II, DVT with PE; PE, pulmonary embolism; DVT, deep vein thrombosis.

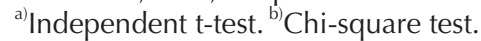

more common in the group without PE with only marginal significance. Other factors were similar in two groups. Multiple logistic regression analysis data shown in Table 3 revealed that infection was the only clinical risk factor for PE $(10.475$; $95 \%$ confidence interval, 1.608-68.221; $\mathrm{P}=0.01$ ).

Initial laboratory findings including white blood cell count, erythrocyte sedimentation rate, C-reactive protein, hemoglobin,
Table 3. Multiple logistic regression analysis of clinical risk factors for pulmonary embolism

\begin{tabular}{lccc}
\hline \multicolumn{1}{c}{ Risk factor } & P-value & Odd ratio & \multicolumn{1}{c}{$95 \% \mathrm{Cl}$} \\
\hline Diabetes, no:yes & 0.192 & 0.231 & $0.026-2.083$ \\
Hypertension, no:yes & 0.241 & 0.477 & $0.138-1.644$ \\
Varicose vein, no:yes & 0.405 & 0.209 & $0.005-8.354$ \\
Surgery, no:yes & 0.950 & 1.042 & $0.285-3.814$ \\
Infection, no:yes & 0.014 & 10.475 & $1.608-68.221$ \\
Pneumonia, no:yes & 0.655 & 0.561 & $0.045-7.074$ \\
$\quad$ Congestive heart failure, & 0.822 & 0.798 & $0.105-6.059$ \\
$\quad$ no:yes & & & \\
Chronic renal failure, & 0.195 & 0.213 & $0.021-2.205$ \\
$\quad$ no:yes & & & \\
Bed-ridden status, no:yes & 0.999 & 0 & 0 \\
$\quad$ History of DVT, no:yes & 0.412 & 1.689 & $0.483-5.906$ \\
Paralysis, no:yes & 0.999 & 0 & 0 \\
\hline
\end{tabular}

$\mathrm{Cl}$, confidence interval; DVT, deep vein thrombosis.

Table 4. Laboratory tests

\begin{tabular}{|c|c|c|c|}
\hline Laboratory test & Group I (PE -) & Group II (PE +) & P-value \\
\hline No. of patients & $54(47.4)$ & $60(52.6)$ & \\
\hline $\begin{array}{l}\text { White blood cell } \\
\text { count }\left(\times 10^{3} / \mu \mathrm{L}\right)\end{array}$ & $8.3 \pm 2.9$ & $8.8 \pm 3.6$ & 0.474 \\
\hline $\begin{array}{l}\text { Erythrocyte } \\
\text { sedimentation rate } \\
(\mathrm{mm} / \mathrm{hr})\end{array}$ & $24.9 \pm 22.3$ & $18.5 \pm 14.0$ & 0.158 \\
\hline $\begin{array}{l}\text { C-reactive protein } \\
(\mathrm{mg} / \mathrm{dL})\end{array}$ & $2.9 \pm 4.0$ & $4.1 \pm 8.0$ & 0.421 \\
\hline Hemoglobin (g/dL) & $11.9 \pm 1.8$ & $12.3 \pm 2.2$ & 0.442 \\
\hline Platelets $\left(\times 10^{3} / \mu \mathrm{L}\right)$ & $218.0 \pm 69.8$ & $215.3 \pm 79.7$ & 0.870 \\
\hline Fibrinogen (mg/dL) & $340.2 \pm 108.9$ & $352.5 \pm 84.2$ & 0.756 \\
\hline D-dimer $(\mu \mathrm{g} / \mathrm{mL})$ & $15.6 \pm 10.6$ & $10.6 \pm 7.2$ & 0.487 \\
\hline Antithrombin III (\%) & $88.3 \pm 35.5$ & $97.3 \pm 10.4$ & 0.695 \\
\hline
\end{tabular}

Values are presented as number $(\%)$ or mean \pm standard deviation.

Group I, DVT without PE; group II, DVT with PE; PE, pulmonary embolism; DVT, deep vein thrombosis.

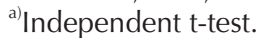

platelets, fibrinogen, D-dimer, and antithrombin III levels were similar in 2 groups (Table 4).

The mean value for the shortest length between the posterior wall of RCIA and anterior border of SB in group I and group II was $6.7 \pm 3.5 \mathrm{~mm}$ and $11.3 \pm 3.7 \mathrm{~mm}$, respectively. Independent t-test identified that this length was significantly shorter in the group without PE (group I; $\mathrm{P}<0.001$ ). Subsequently, the length at which the risk of PE increases was determined using ROC curve analysis to be $7.63 \mathrm{~mm}$ (sensitivity, 90.6\%; specificity, $70.0 \%$; positive predictive value, $77 \%$; negative predictive value, $87 \%$; area under the curve $=0.858)$ (Fig. 2). 


\begin{tabular}{ccc}
\hline $\begin{array}{c}\text { Diameter } \\
(\mathrm{mm})\end{array}$ & $\begin{array}{c}\text { Sensitivity } \\
(\%)\end{array}$ & $\begin{array}{c}\text { Specificity } \\
(\%)\end{array}$ \\
\hline 6.74 & 90.6 & 60.0 \\
7.08 & 90.6 & 65.0 \\
\hline 7.63 & 90.6 & 70.0 \\
\hline 7.93 & 87.5 & 70.0 \\
8.03 & 84.4 & 70.0 \\
\hline
\end{tabular}

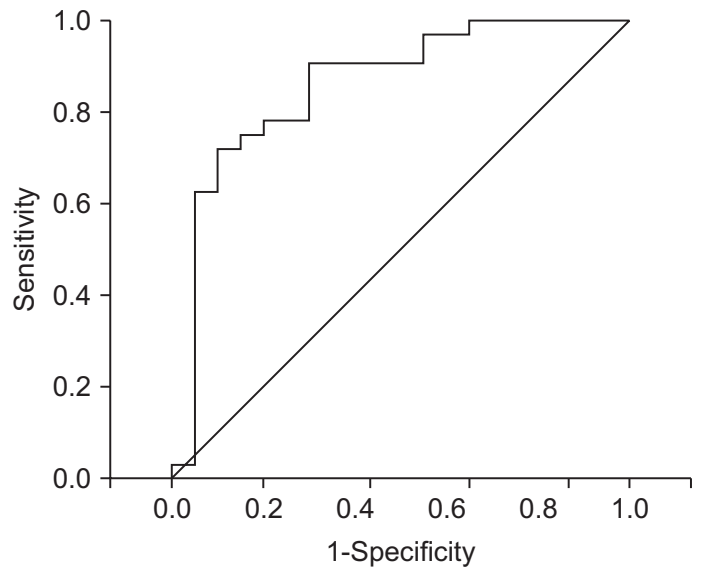

Fig. 2. Receiver operating characteristics curve analysis. A length exceeding $7.63 \mathrm{~mm}$ between the posterior wall of the common iliac artery and anterior border of the spinal body was the best value to predict the pulmonary embolism in patients with lower extremity deep vein
thrombosis.

\section{DISCUSSION}

This study demonstrates that infection is associated with a markedly increased risk for the development of PE in patients with LEDVT. Although the diabetes and hypertension were more common in the group without $\mathrm{PE}$, these factors did not affect PE development. The length between the posterior wall of RCIA and the anterior border of SB was shorter in the group without $\mathrm{PE}$ indicating a protective influence concerning migration of thrombus into the pulmonary circulation.

Infection has been linked to the development of VTE [8-10]. Infection can have direct consequences and indirect effects, the latter being due to the effect on the immune system. The resulting inflammatory process and the coagulation and fibrinolytic processes share common pathways, explaining why infection is associated with thrombosis [8]. In addition, integrin $\beta 1, \beta 2$, and $\beta 3$ subunits can be increased in patients with infectious diseases as the core proteins of venous thrombosis [11,12]. In our study, 15 patients had infection.

Infection was the only clinical risk factor for PE in patients with DVT in the present study. Acute infection is associated to an increase in the risk of both DVT and PE, suggesting a role for acute infections in triggering such events $[10,13]$. Indeed, information about the temporal event could not be obtained from this data.

We analyzed pneumonia separately as a risk of PE in patients with DVT. Although patients with PE and concomitant pneumonia are uncommon, pneumonia is associated with an increased risk of PE. In one study, 36 of 794 patients (5\%) had coexisting pneumonia [14]. In a retrospective cohort study, 724 of 2,378 patients (30.3\%) hospitalized with community acquired pneumonia displayed increased D-dimer levels [15].

Iliac vein compression (also known as May-Thurner syndrome) increases the development of DVT on ipsilateral lower extremity. The odds of left DVT increase by a factor of 1.68 for each millimeter decrease in LCIV diameter [16]. However, it has also been reported in a case control study that stenosis of the CIV may have a protective effect against embolization to the lungs of large DVT that develops in the lower extremities; unilateral DVT patients with ipsilateral CIV lumen $\leq 4 \mathrm{~mm}$ had a $83 \%$ lower risk of developing symptomatic PE compared with those with a CIV lumen exceeding $4 \mathrm{~mm}$ [7]. In our study, the cutoff value for the effect of iliac vein compression on PE prevention was $7.63 \mathrm{~mm}$.

Intravascular ultrasound has been suggested as the modality of choice for evaluation of luminal diameter of iliac vein [17-19]. Because of the ability to perform exact measurements of the venous dimensions with intravascular ultrasound, it can assist in the diagnosis and classification of iliac vein compression syndrome. However, CT imaging provides detailed anatomic information, making it a fast, efficient, reliable, and popular diagnostic tool.

This study has several limitations. Due to the retrospective study design, difficulties concerning accessibility of information and its accuracy were encountered. In addition, the relatively small sample size may have limited the preciseness of the statistical analysis, thus reducing the generalization and imminent clinical utility of the data. CT imaging to measure the length between CIA and SB is another limitation, since it could not precisely reflect the luminal diameter of the compressed iliac vein. Intravascular ultrasound should be used to measure the luminal diameter of iliac vein in further studies.

In conclusion, infection is a significant and independent risk factor for PE in patients with LEDVT. Longer length, especially more than $7.63 \mathrm{~mm}$ between CIA and SB, might pose a risk of PE in patients with LEDVT. Our results should be further investigated in larger prospective studies.

\section{CONFLICTS OF INTEREST}

No potential conflict of interest relevant to this article was reported. 


\section{REFERENCES}

1. Heit JA. Epidemiology of venous thromboembolism. Nat Rev Cardiol 2015;12:464 74.

2. Heit JA. Venous thromboembolism: disease burden, outcomes and risk factors. J Thromb Haemost 2005:3:1611-7.

3. Jang MJ, Bang SM, Oh D. Incidence of venous thromboembolism in Korea: from the Health Insurance Review and Assessment Service database. J Thromb Haemost 2011;9:85-91.

4. Meignan M, Rosso J, Gauthier H, Brunengo F, Claudel S, Sagnard L, et al. Systematic lung scans reveal a high frequency of silent pulmonary embolism in patients with proximal deep venous thrombosis. Arch Intern Med 2000;160:159-64.

5. Stein PD, Matta F, Musani MH, Diaczok B. Silent pulmonary embolism in patients with deep venous thrombosis: a systematic review. Am J Med 2010;123:426-31.

6. Fraser DG, Moody AR, Martel A, Morgan PS. Re-evaluation of iliac compression syndrome using magnetic resonance imaging in patients with acute deep venous thromboses. J Vasc Surg 2004;40:604-11.

7. Chan KT, Popat RA, Sze DY, Kuo WT, Kothary N, Louie JD, et al. Common iliac vein stenosis and risk of symptomatic pulmonary embolism: an inverse correlation. J Vasc Interv Radiol 2011;22:133-41.

8. Epaulard O, Foote A, Bosson JL. Chronic
Infection and Venous Thromboembolic Disease. Semin Thromb Hemost 2015;41: 644-9.

9. Obi AT, Pannucci CJ, Nackashi A, Abdullah $\mathrm{N}$, Alvarez R, Bahl V, et al. Validation of the caprini venous thromboembolism risk assessment model in critically Ill surgical patients. JAMA Surg 2015;150:941-8.

10. Smeeth L, Cook C, Thomas S, Hall AJ, Hubbard R, Vallance P. Risk of deep vein thrombosis and pulmonary embolism after acute infection in a community setting. Lancet 2006;367:1075-9.

11. Song Y, Wang L, Yang F, Wu X, Duan Q, Gong Z. Increased expressions of integrin subunit $\beta 1, \beta 2$ and $\beta 3$ in patients with acute infection. Int J Med Sci 2015;12:63943.

12. Song Y, Yang F, Wang L, Duan Q, Jin Y, Gong $Z$. Increased expressions of integrin subunit $\beta 1, \beta 2$ and $\beta 3$ in patients with venous thromboembolism: new markers for venous thromboembolism. Int J Clin Exp Med 2014;7:2578-84

13. Alikhan R, Cohen AT, Combe S, Samama MM, Desjardins L, Eldor A, et al. Risk factors for venous thromboembolism in hospitalized patients with acute medical illness: analysis of the MEDENOX Study. Arch Intern Med 2004:164:963-8.

14. Cha SI, Choi KJ, Shin KM, Lim JK, Yoo SS, Lee J, et al. Clinical characteristics of pulmonary embolism with concomitant pneumonia. Blood Coagul Fibrinolysis 2016;27:281-6.

15. Zhang Y, Zhou Q, Zou Y, Song X, Xie S, Tan M, et al. Risk factors for pulmonary embolism in patients preliminarily diagnosed with community-acquired pneumonia: a prospective cohort study. J Thromb Thrombolysis 2016;41:619-27.

16. Carr S, Chan K, Rosenberg J, Kuo WT, Kothary N, Hovsepian DM, et al. Correlation of the diameter of the left common iliac vein with the risk of lower-extremity deep venous thrombosis. J Vasc Interv Radiol 2012;23:1467-72.

17. Forauer AR, Gemmete JJ, Dasika NL, Cho KJ, Williams DM. Intravascular ultrasound in the diagnosis and treatment of iliac vein compression (May-Thurner) syndrome. J Vasc Interv Radiol 2002;13: 523-7.

18. Ahmed HK, Hagspiel KD. Intravascular ultrasonographic findings in May-Thurner syndrome (iliac vein compression syndrome). J Ultrasound Med 2001;20:251-6.

19. Byun E, Mayeda GS. Intravascular ultrasound diagnosis of a venous obstruction not visualized by conventional venography: a case report. Catheter Cardiovasc Interv 2002;57:61-4. 